\title{
Modelo de degeneração do disco intervertebral por punção da cauda de ratos Wistar: avaliação histológica e radiográfica
} Injury model by needle puncture of the Wistar rats' tail: histological
and radiographic assessments Modelo de degeneración del disco intervertebral por punción de la cola de ratas Wistar: evaluación histológica y radiográfica

\author{
Ana Carolina de C. Issy Pereira' \\ Vitor Castania' \\ Joost J. A. de Jong ${ }^{2}$ \\ Helton L. A. Defino ${ }^{3}$ \\ Dimitrius Leonardo Pitol ${ }^{4}$ \\ Mamie Mizusaki lyomasa ${ }^{5}$ \\ Elaine Del Bel ${ }^{5}$
}

\section{RESUMO}

Objetivo: descrever a caracterização histológica e radiográfica do método de indução da degeneração do disco intervertebral da cauda de ratos Wistar induzida por meio de punção. Métodos: ratos Wistar machos adultos foram anestesiados, radiografados e submetidos à punção dos discos intervertebrais localizados entre a sexta e a sétima e a oitava e nona vértebras coccígeas. Para a punção foi utilizada agulha de 20G, que foi introduzida até o ânulo fibroso, e foi realizada dupla rotação de $360^{\circ}$, mantendo-se a mesma posição durante 30 segundos antes da retirada. O disco intermediário aos segmentos lesados (7-8) não foi puncionado e foi utilizado como controle. Foi selecionado o período pós-lesão de 30 dias $(n=9)$ para sacrifício e análise dos discos intervertebrais.

\section{ABSTRACT}

Objective: to report the induction of intervertebral disc degeneration of the rat caudal spine by needle puncture and its radiographic and histologic characterization. Methods: adult male Wistar rats were anesthetized, submitted to the X-Ray and then to the needle puncture (20G) of intervertebral disc between the sixth and seventh (proximal segment) and the eighth and ninth (distal segment) coccygeal vertebrae. Radiographies were taken 30 days after lesion for analysis of intervertebral disc height. The intermediate disc (78) to injured segments was not punctured and was considered as control. All segments were removed, fixed and demineralized, processed and stained with Hematoxylin-Eosin for histological evaluation. Results:
\end{abstract}

\section{RESUMEN}

Objetivo: describir la caracterización histológica y radiográfica del método de inducción de la degeneración del disco intervertebral de la cola de ratas Wistar, inducida por medio de la punción. Métodos: ratas Wistar machos adultos fueron anestesiados, radiografiados y sometidos a la punción de los discos intervertebrales localizados, entre la sexta y la séptima; y la octava y novena vértebras coccigeas. Para la punción, fue utilizada una aguja de $20 \mathrm{G}$, que fue introducida hasta el ánulo fibroso, y fue realizada una dupla rotación de $360^{\circ}$, manteniendo esta posición durante 30 segundos, previamente a la retirada. El disco intermediario a los segmentos lesionados (7-8) no fue puncionado y fue considerado como control. Fue seleccionado el periodo post-lesión de 30 días $(n=9)$ para sacrificio y análisis de

\footnotetext{
Trabalho realizado com apoio do Programa Nacional de Pós-Doutorado - PNPD - Coordenação de Aperfeiçoamento de Pessoal de Nível Superior - CAPES

'Aluno de Pós-Doutorado do Departamento de Biomecânica, Reabilitação e Medicina do Aparelho Locomotor da Universidade de São Paulo - USP - Ribeirão Preto (SP), Brasil.

2Pós-graduando (Mestrado) do Departamento de Engenharia Médica da Eindhoven University of Technology, Eindhoven, The Netherlands.

${ }^{3}$ Professor Titular do Departamento de Biomecânica, Reabilitação e Medicina do Aparelho Locomotor da Universidade de São Paulo - USP - Ribeirão Preto (SP), Brasil.

${ }^{4}$ Técnico do Departamento de Morfologia, Estomatologia e Fisiologia da Faculdade de Odontologia de Ribeirão Preto da Universidade de São Paulo - USP Ribeirão Preto (SP), Brasil.

${ }^{5}$ Professor Associado do Departamento de Morfologia, Estomatologia e Fisiologia da Faculdade de Odontologia de Ribeirão Preto da Universidade de São Paulo USP - Ribeirão Preto (SP), Brasil.
} 
Os animais foram radiografados 30 dias após a lesão para análise da altura do disco intervertebral. Os segmentos da cauda foram removidos, fixados e desmineralizados, processados e corados com Hematoxilina-Eosina para avaliação histológica. Resultados: a análise radiográfica revelou a redução significativa da altura dos discos lesados em relação ao controle. A avaliação histológica revelou alterações no núcleo pulposo e ânulo fibroso dos discos lesados em relação ao controle. Não foram observadas diferenças na intensidade de lesão entre os discos proximal e distal. Conclusão: a degeneração do disco intervertebral da cauda de ratos Wistar induzida por meio de punção mostrou ser método reprodutível para estudo da degeneração do disco intervertebral. Esse modelo mostrou validade para avaliação experimental de novas intervenções terapêuticas nos processos de degeneração do disco intervertebral.

DESCRITORES: Degeneração do disco intervertebral; Histologia; Disco intervertebral; Ratos Wistar

radiographic analysis revealed significant reduction in disc height of lesioned discs compared to control. Similarly, histological analysis revealed significant changes in the nucleus pulposus and annulus fibrosus of the lesioned discs (proximal and distal) relative to the control. There was no difference in the intensity of injury between the proximal and distal discs. Conclusion: the experimental model of tail intervertebral disc degeneration by needle puncture reproduced the steps of the intervertebral disc degeneration, assessed by different instruments, and it can be used for experimental evaluation of new therapeutic interventions for intervertebral disc degeneration process.

KEYWORDS: Intervertebral disc degeneration; Histology; Intervertebral disc; Rats, Wistar los discos intervertebrales. Los animales fueron radiografiados 30 días después de la lesión para análisis de la altura del disco intervertebral. Los segmentos de la cola fueron removidos, fijados y desmineralizados, procesados y coloreados con hematoxilina-eosina para evaluación histológica. Resultados: el análisis radiográfico mostró una reducción significativa de la altura de los discos lesionados en relación al control. La evaluación histológica mostró alteraciones en el núcleo pulposo y el ánulo fibroso de los discos lesionados en relación al control. No fueron observadas diferencias en la intensidad de la lesión entre los discos proximal y distal. Conclusiónes: la degeneración del disco intervertebral de la cola de ratas Wistar inducida por medio de punción mostró ser un método reproducible para el estudio de la degeneración del disco intervertebral. Ese modelo mostró validez para la evaluación experimental de nuevas intervenciones terapéuticas en los procesos de la degeneración del disco intervertebral.

DESCRIPTORES: Degeneración del disco intervertebral; Histología; Disco intervertebral; Ratas Wistar

\section{INTRODUÇÃO}

O estudo dos fenômenos biológicos e biomecânicos associados com a degeneração do disco intervertebral tem sido motivado pelo crescente impacto socioeconômico da dor lombar na população ${ }^{1}$. A degeneração do disco intervertebral é caracterizada por um conjunto complexo de alterações morfológicas, bioquímicas e biológicas que acarretam a sua disfunção mecânica, frequentemente acompanhada de dor em muitos indivíduos ${ }^{2,3}$. Modelos experimentais in vitro e in vivo têm sido desenvolvidos com o objetivo de reproduzir as etapas da degeneração do disco intervertebral ${ }^{2,3}$. No entanto, a relevância dos estudos experimentais, apesar de possuírem o mérito da elucidação de questionamentos específicos sobre a degeneração do disco intervertebral de humanos, deve ser cautelosamente interpretada.

Os modelos animais são utilizados com frequência para o estudo da degeneração do disco intervertebral por permitirem a avaliação padronizada dos fenômenos biológicos, bioquímicos e morfológicos desde as suas fases iniciais. Desse modo, representam ferramentas úteis para o desenvolvimento de novas intervenções terapêuticas e para o esclarecimento dos mecanismos fisiopatológicos envolvidos na degeneração do disco ${ }^{2}$. Diferentes espécies como coelhos ${ }^{4}$, camundongos ${ }^{5}$, ratos $^{6}$, bovinos ${ }^{7}$ e ovinos ${ }^{8}$ têm sido utilizadas nos modelos de degeneração do disco intervertebral. A degeneração induzida pode ser obtida por meio de alterações mecânicas do disco intervertebral, tais como modificações posturais, suspensão pela cauda, corte com bisturi do ânulo fibroso, carga axial ou punção com agulha do ânulo fibroso ${ }^{3,2,9-11}$. Adicionalmente, a degeneração do disco pode ocorrer espontaneamente, sendo observada, por exemplo, em animais geneticamente modificados ou em linhagens específicas ${ }^{12}$ (exemplo: Sand rats).

O modelo de lesão do disco intervertebral por meio de punção utilizando agulhas de 16 a $21 \mathrm{G}$ foi recentemente desenvolvido e reproduz as alterações morfológicas e bioquímicas similares àquelas observadas nos processos degenerativos dos discos intervertebrais humanos ${ }^{13}$. Tem sido proposto que a degeneração induzida por esse método seja mais lenta, comparada com a produzida pela incisão do ânulo fibroso com lâmina de bisturi. A degeneração 
mais lenta e progressiva, semelhante à degeneração que ocorre nos humanos, seria mais adequada para a avaliação da eficácia de novas intervenções terapêuticas ${ }^{13}$.

O objetivo deste estudo foi relatar a indução da degeneração do disco intervertebral da cauda de ratos Wistar por punção com agulha, determinando sua caracterização histológica e radiográfica.

\section{MÉTODOS}

Foram utilizados nove ratos Wistar machos (300-350 g) provenientes do Biotério Central da Universidade de São Paulo, campus Ribeirão Preto. Os animais foram mantidos em grupos de quatro animais por caixa em temperatura ambiente controlada de $23^{\circ} \mathrm{C}( \pm 1)$, ciclo claro-escuro de 12 horas e alimentação ad libitum. Todos os experimentos foram conduzidos de acordo com as normas do Comitê de Ética em Experimentação Animal da Universidade de São Paulo (CETEA).

Os animais foram anestesiados com associação de ketamina $(88 \mathrm{mg} / \mathrm{kg})$ e xilazina $(12 \mathrm{mg} / \mathrm{kg})$ por via intraperitoneal. Após antissepsia da cauda com álcool iodado, os discos intervertebrais entre a sexta e a sétima e a oitava e nona vértebras coccígeas foram percutaneamente perfurados com agulha de $20 \mathrm{G}$ com o auxílio de fluoroscopia para a identificação dos espaços discais (Figura 1). A agulha foi introduzida até o ânulo fibroso contralateral, foi realizada a sua dupla rotação de $360^{\circ}$ e mantida na mesma posição no interior do disco intervertebral durante 30 segundos, de acordo com a recomendação de Zhang et al. ${ }^{13}$ e Han et al. ${ }^{14}$. O disco intervertebral intermediário aos discos lesados (nível 7-8) não foi puncionado, sendo utilizado como controle. Os animais foram sacrificados 30 dias após a lesão. O sacrifício dos animais foi realizado com dose letal

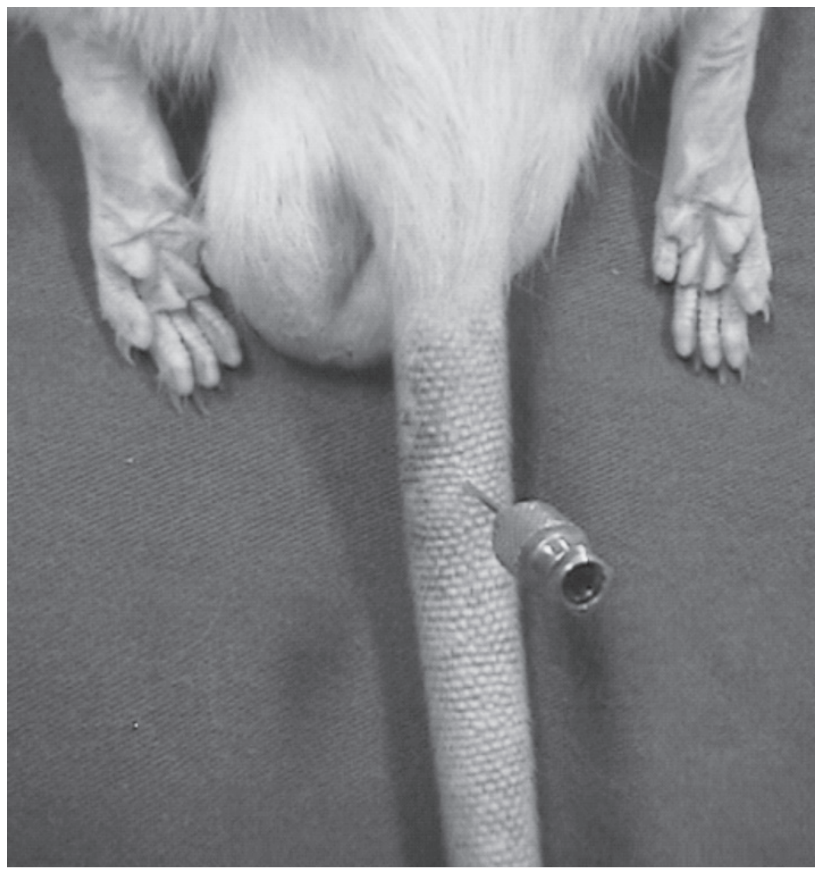

Figura 1

Fotografia ilustrando a punção do disco intervertebral da cauda do rato com agulha. de uretana, e o segmento da cauda abrangendo os discos puncionados e o disco controle foram removidos e preparados para análise histológica em microscopia de luz com utilização de escore proposto por Norcross et al. ${ }^{15}$.

\section{Preparo do tecido para avaliação histológica}

$\mathrm{O}$ segmento da cauda removido foi fixado em paraformaldeído (PFA 4\%) em PB 0.1M, pH 7.4, durante 24 horas, e, em seguida, dissecado e descalcificado em EDTA 10\% durante 30 dias. Foram realizadas trocas semanais da solução de EDTA até a completa desmineralização do tecido ósseo. O tecido foi processado em parafina e secções sagitais com espessura de $5 \mu \mathrm{m}$ foram obtidas em micrótomo. $\mathrm{O}$ material foi corado pela técnica de Hematoxilina-Eosina e analisado em microscópio Leica ${ }^{\circledR}$ com amplificação de 5X.

\section{Análise radiográfica e avaliação da altura do disco intervertebral (DHI)}

Todos os animais tiveram sua cauda radiografada imediatamente antes da realização da punção e após 30 dias da indução da lesão. Para a realização do teste radiográfico foi utilizada escala milimétrica confeccionada em material radiopaco para orientação e reconhecimento do nível da lesão. As tomadas radiográficas foram realizadas em aparelho Siemens Multix ${ }^{\circledR}$ padrão Kv:35, tempo de exposição de 2,5 ms e foco fino de 1 m. Para obtenção de melhor resolução das imagens foi utilizado filme radiográfico $\operatorname{Kodak}^{\circledR}$ MIN R2000. As radiografias foram utilizadas para o cálculo da altura do disco intervertebral segundo técnica apresentada por Massuda et al. ${ }^{16}$. Esse método utiliza o comprimento da vértebra proximal (PV), distal (DV) e do disco intervertebral (DH) para normalização da altura do disco (Figura 2). Para obtenção da altura do disco intervertebral (DHI) é utilizada a seguinte fórmula:

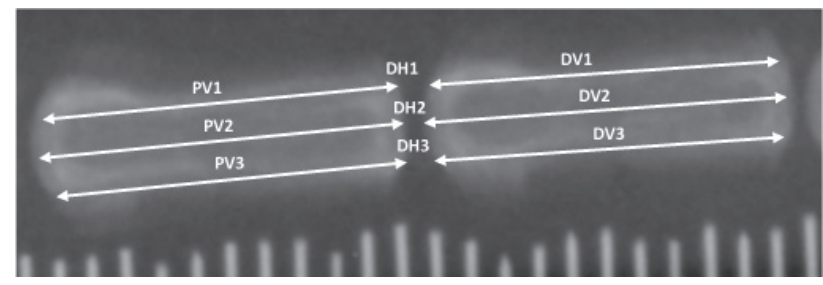

Figura 2

Radiografia da cauda ilustrando as medidas utilizadas para 0 cálculo da altura do disco intervertebral.

DHI (Disc Height Index $)=2 *(\mathrm{DH} 1+\mathrm{DH} 2+\mathrm{DH} 3) /$ $((\mathrm{PV} 1+\mathrm{PV} 2+\mathrm{PV} 3)+(\mathrm{DV} 1+\mathrm{DV} 2+\mathrm{DV} 3)$

$\% \mathrm{DHI}=(\mathrm{DHI}$ pós-lesão/DHI pré-lesão)*100

A análise da imagem radiográfica foi realizada utilizando-se programa Image J, desenvolvido pelo U.S. National Intitutes of Health, de domínio público (http://rsb.info.nih. gov/nih-image/).

\section{Avaliação histológica do disco intervertebral}

As alterações histológicas do ânulo fibroso e núcleo pulposo foram analisadas de acordo com escore proposto por Norcross et al. ${ }^{15}$, que classifica as alterações do ânulo fibroso e 
do núcleo pulposo em cinco categorias, que variam desde a normalidade (5) até a degeneração grave (1), Tabela 1.

\section{TABELA 1 - Escore Histológico proposto por Norcross et al., 2003.}

\begin{tabular}{l} 
Núcleo pulposo (NP) \\
\hline 5- Grande, com abaulamento da cavidade central e \\
material abundante; > 2/3 da altura do DIV*; limites \\
nítidos com o mínimo de interrupção. \\
4- Tamanho ligeiramente reduzido da cavidade central com \\
algum material do NP presente; > 1 /3 da altura do DIV e \\
<2/3; pode apresentar rompimento mínimo dos limites. \\
3- Redução altura acentuada da cavidade com preservação \\
mínima de material do NP; compartimentalização; total da \\
cavidade > 1/3 da altura do DIV e < 2/3. \\
2- Grave prejuízo do NP ; cavidade mínima; cavidade total \\
< 1/3 da altura do DIV e > O; presença de algumas ilhas \\
circundadas por células do NP. \\
1- Obliteração completa da cavidade sem células do NP. \\
Ânulo Fibroso
\end{tabular}

5- Lamelas discretas, bem opostas, com abaulamento sem dobras. Defeito mínimo da preparação com fenda radial simples (a).

4- Lamelas discretas, não tão opostas; dobras mínimas podem estar presentes, fibras continuam bem organizadas, mas com fenda radial complexa (b).

3- Dobras moderadas a severas, lamelas relativamente bem opostas, moderada fragmentação da lamela, fibras do ânulo continuam bem organizadas

2- Dobras severas e distorção de lamelas pobremente opostas, severa fragmentação das lamelas, pequenas regiões com material fibroso desorganizado.

1- Dobras severas, distorção e fragmentação da lamela extensa quantidade de material fibroso desorganizado substituindo a lamela central.

* disco intervertebral; (a) lacunas radiais entre as lamelas do ânulo fibroso com fragmentação mínima; (b) lacunas radiais, transversas e/ou oblíquas entre as lamelas com fragmentação significativa.

\section{Análise estatística}

A DHI foi analisada por meio de análise de variância - one way ANOVA. As alterações histológicas foram analisadas por meio de MANOVA de medidas repetidas, tendo como medida repetida os segmentos (proximal e distal), e como medida independente a condição (lesado ou controle). As diferenças individuais foram apontadas pelo teste post hoc Duncan, $\mathrm{p}<0,05$.

\section{RESULTADOS}

\section{Análise radiográfica}

Foram observadas reduções significativas da DHI nos segmentos puncionados proximal (6-7) e distal (8-9) em relação ao controle (7-8), aos 30 dias $[\mathrm{F}(2,26)=12,18$; $\mathrm{p}=0,001$; Figura 3] após a punção (one way ANOVA, seguida de teste post hoc Duncan, $\mathrm{p}<0,05$, Figura 4). Não foram observadas diferenças significativas entre os discos intervertebrais puncionados (proximal e distal). disco controle disco puncionado proximal disco puncionado distal

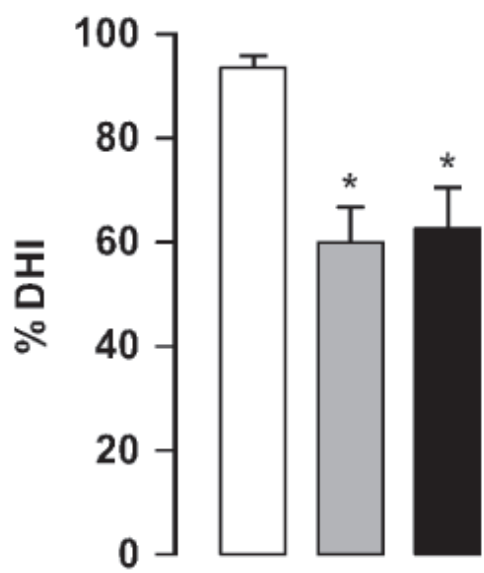

Figura 3

Gráfico ilustrando a porcentagem de redução da altura do disco intervertebral (\%DHI) 30 dias após a lesão. Os discos intervertebrais (proximal e distal) apresentaram redução significativa da \%DHI em relação ao disco controle. ${ }^{*} p<0,05$ em relação ao disco controle. One way ANOVA, post hoc Duncan.
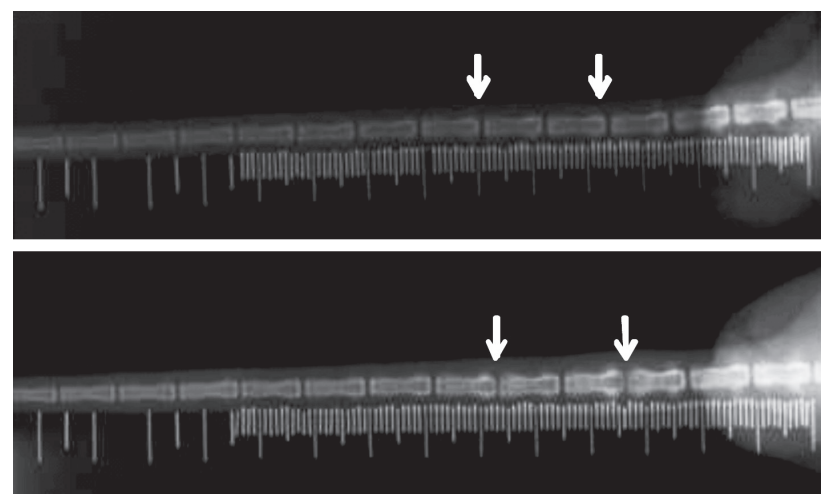

Figura 4

Radiografias da cauda do animal realizadas antes da punção (foto superior) e 30 dias após a punção do disco intervertebral (foto inferior). As setas indicam os segmentos 6-7 e 8-9 antes e após a punção. Ao lado da imagem das vértebras da cauda do animal pode ser observada a escala confeccionada em material radiopaco utilizada para a identificação dos discos puncionados e disco controle.

\section{Análise histológica}

Foram encontradas alterações significativas no núcleo pulposo e no ânulo fibroso nos discos intervertebrais proximal (6-7) e distal (8-9) puncionados em relação ao controle (78), 30 dias após a punção $[\mathrm{F}(2,24)=25,26 ; \mathrm{p}=0,001$; Duncan, $\mathrm{p}<0,05$; Tabela 2]. Nos discos intervertebrais submetidos à punção foi observada grande diminuição do núcleo pulposo e ampla desorganização do ânulo fibroso. A análise estatística (MANOVA de medidas repetidas) mostrou que não há diferença se a lesão é realizada no segmento proximal ou distal da cauda aos 30 dias após a punção 
[segmento $F(1,24)=3,062 ; p=0,093$; interação segmento versus lesão $\mathrm{F}(2,24)=0,812 ; \mathrm{p}=0,456]$. A Figura 5 representa segmentos controle e lesado submetidos à técnica de Hematoxilina-Eosina.

\section{TABELA 2 - Escore Histológico}

\begin{tabular}{lcc}
\hline Disco & Núcleo pulposo & Ânulo fibroso \\
\hline controle & $4,33 \pm 0,25$ & $4,33 \pm 0,25$ \\
puncionado proximal & $1,33 \pm 0,18^{*}$ & $1,67 \pm 0,25^{*}$ \\
puncionado distal & $2,00 \pm 0,47^{*}$ & $2,44 \pm 0,50 *$ \\
\hline
\end{tabular}

Resultados apresentados na forma de média \pm EPM. Os escores dos discos puncionados apresentaram redução significativa em relação ao disco controle. ${ }^{*} \mathrm{p}<0,05$ em relação ao disco controle. MANOVA, post hoc Duncan.
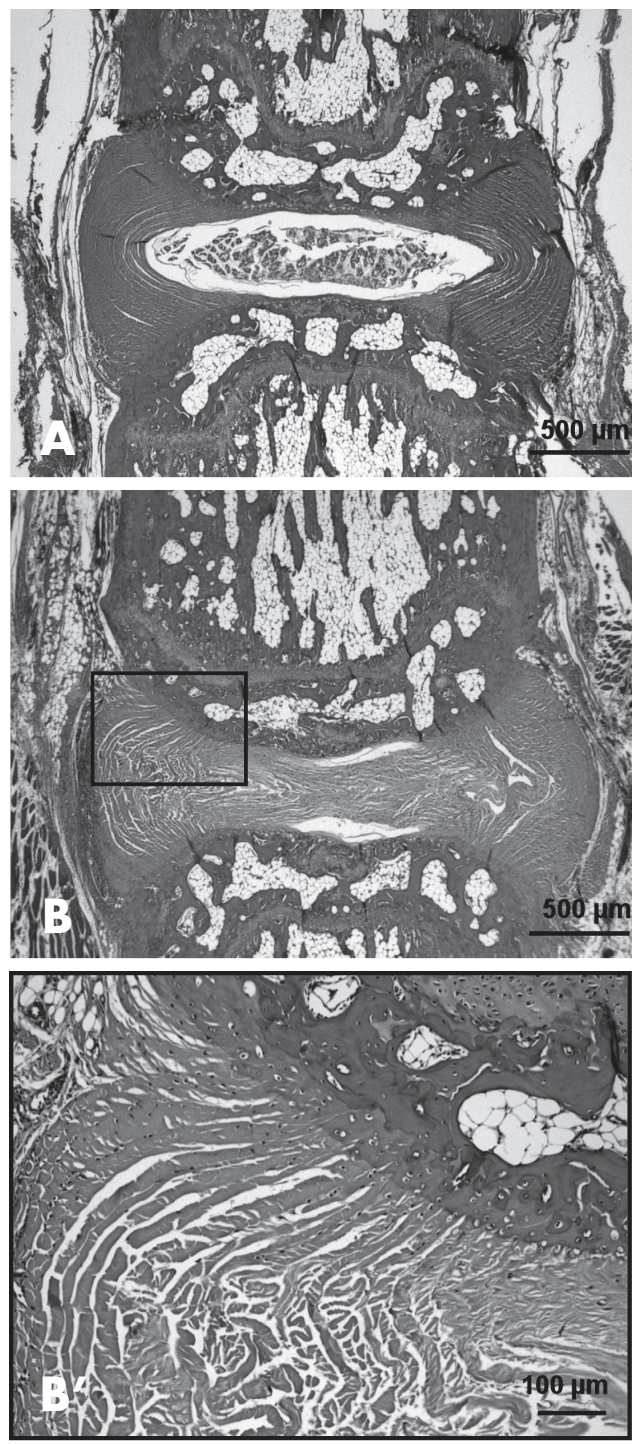

Figura 5

Fotomicrografias do disco intervertebral da cauda de rato Wistar. Disco controle (A) com aumento de $5 \mathrm{X}$ e disco puncionado com agulha de $20 \mathrm{G} 30$ dias após a punção com aumento de 5X (B) ou 10X ( $\left.B^{\prime}\right)$ corados pela técnica de Hematoxilina-Eosina. Observar a ausência de células do núcleo pulposo, completa obliteração da cavidade e desorganização das lamelas do ânulo fibroso.

\section{DISCUSSÃO}

A magnitude e o impacto socioeconômico da doença discal degenerativa tem despertado o interesse no estudo das possibilidades terapêuticas da reparação do disco intervertebral. O surgimento de novas intervenções terapêuticas relacionadas com a biologia molecular ${ }^{14}$, engenharia de te$\operatorname{cidos}^{17}$, transplante de células ${ }^{18}$ ou fatores de crescimento ${ }^{19}$ aumentou a necessidade do desenvolvimento de modelos experimentais para a viabilização dos estudos. A degeneração do disco intervertebral em animais deve reproduzir as etapas da degeneração do disco intervertebral, evidenciando alterações morfológicas e bioquímicas semelhantes às observadas nos discos humanos. Para facilitar a execução do estudo e viabilizar o seu custo e financiamento, deve-se utilizar animais de pequeno porte. Os roedores são utilizados como modelo experimental para o estudo da degeneração do disco intervertebral devido à facilidade da sua utilização e ao baixo custo $^{20}$.

A coluna lombar é o principal alvo da lesão do disco intervertebral. No entanto, para a indução da lesão nessa região é necessária a abordagem anterior do disco intervertebral, que representa procedimento cirúrgico adicional associado a riscos e aumento da morbidade ${ }^{15,21}$. A dissecção excessiva ou a irritação dos tecidos adjacentes pode induzir a formação de osteofitos que interferem na avaliação da degeneração do disco intervertebra ${ }^{16}$. A lesão do disco intervertebral induzida na coluna lombar possui ainda a desvantagem de não ser detectada precocemente pelos métodos radiológicos e histológicos convencionais ${ }^{20}$.

A lesão cirúrgica do ânulo fibroso inicia o processo de degeneração do disco intervertebral devido à herniação e à despressurização nuclear ${ }^{3}$, e classicamente é realizada por meio da anulotomia ${ }^{13}$. A punção com agulha é outra modalidade de lesão estrutural do disco intervertebral, capaz de promover as alterações morfológicas e bioquímicas de modo mais lento que as produzidas pela anulotomia com lâminas ${ }^{16}$. Esse tipo de punção foi inicialmente utilizada em modelos experimentais utilizando coelhos ${ }^{16,22}$ e, posteriormente, $\operatorname{ratos}^{13,14}$. A punção do disco intervertebral com agulhas na coluna lombar de coelhos ${ }^{16,22,23}$ apresenta a desvantagem do custo e manuseio do animal quando comparado com o modelo utilizando ratos. Esses animais apresentam as vantagens do baixo custo e manuseio mais fácil, além da reprodutibilidade. Essas características do modelo experimental utilizando a punção da cauda com agulha, que permite induzir a degeneração mais lenta do disco intervertebral, foram decisivas para a escolha desse modelo em nossa linha de pesquisa.

Os resultados observados em nosso estudo piloto para a indução da degeneração discal utilizando a punção da cauda de ratos com agulha permitiram a observação de alterações histológicas do núcleo pulposo, ânulo fibroso e alteração radiográfica da altura do disco intervertebral em concordância com os relatos da utilização desse modelo experimenta ${ }^{13,14}$. 
A técnica de indução da degeneração por meio da punção do disco intervertebral da cauda foi realizada segundo critérios apresentados por Han et al. ${ }^{14}$. No entanto, foi selecionada a agulha com calibre de $20 \mathrm{G}$, que representa um valor intermediário àqueles propostos por esses autores. Para o reconhecimento da lesão foram utilizados dois critérios de análise, um radiográfico e outro histológico. As radiografias realizadas antes e após a lesão (30 dias depois) foram utilizadas para o cálculo da altura do disco, segundo critérios propostos por Massuda et al. ${ }^{16}$. A redução nos discos intervertebrais degenerados tem sido utilizada como parâmetro de avaliação nos modelos experimentais $^{14-16}$. Nossos resultados revelaram redução significativa da altura dos discos puncionados, 30 dias após a lesão, em relação ao disco intervertebral controle.

A análise histológica foi realizada segundo o escore proposto por Norcross et al. ${ }^{15}$, que considera as alterações ocorridas no núcleo pulposo e ânulo fibroso. De forma semelhante ao observado com a altura do disco, as alterações histológicas reveladas, tais como a diminuição do núcleo pulposo e a desorganização do ânulo fibroso, foram significativas 30 dias após a punção, em comparação ao controle. De forma interessante, foi observada correlação positiva entre a altura do disco e o escore histológico aos 30 dias após a punção (dados não apresentados). Ou seja, quanto menor a altura do disco, menor o escore obtido, o que significa maior gravidade da degeneração do tecido discal. O disco intervertebral controle localizado entre os discos puncionados e que desenvolveram alterações degenerativas tem sido alvo de críticas do modelo experimental. Nesse estudo, os discos controle não apresentaram alterações detectáveis na análise histológica e radiográfica. Houve manutenção da altura dos discos intervertebrais controle 30 dias após a punção. Deve ser considerado que os discos intervertebrais da cauda não estão submetidos às cargas mecânicas e não apresentam articulações facetárias, atuando em condições mecânicas distintas dos demais segmentos vertebrais. Por isso, não seriam influenciados pelas alterações dos discos adjacentes ${ }^{13,24}$.

Algumas limitações do modelo experimental de degeneração do disco intervertebral devem ser consideradas ao compararmos essa condição com a degeneração que ocorre em humanos, destacando a indução da rápida degeneração do disco intervertebral, diferentes tipos de células do núcleo, persistência da placa epifisária, ausência de carga sobre o disco e os efeitos das pequenas dimensões do disco da cauda sobre a difusão da placa vertebral terminal ${ }^{2,10,26-28}$. No entanto, o modelo experimental de degeneração do disco intervertebral utilizado reproduziu as etapas da degeneração do disco intervertebral avaliada por diferentes instrumentos. Foi eficiente, apresentou baixo custo e, considerando-se essas características, pode ser utilizado como modelo animal para a utilização em grande escala. Em conclusão, a degeneração do disco intervertebral da cauda induzida por punção mostrou validade para avaliação experimental de novas intervenções terapêuticas.

\section{AGRADECIMENTOS}

Ao suporte técnico oferecido por Célia A. da Silva da Faculdade de Odontologia de Ribeirão Preto da Universidade de São Paulo (USP); Mônica Bernardo, do Departamento de Radiologia da Faculdade de Medicina de Ribeirão Preto da USP; e Gilmar de Oliveira, responsável pelo setor de Radiologia da Faculdade de Medicina de Ribeirão Preto da USP/Hospital das Clínicas. Aos professores Marcelo Henrique Nogueira Barbosa, da Clínica Médica, e Carlos Ernesto Garrido Salmon, da Física Médica. Apoio financeiro Projeto Capes/PNPD, Conselho Nacional de Desenvolvimento Científico e Tecnológico (CNPq) e Fundação de Amparo à Pesquisa do Estado de São Paulo (FAPESP).

\section{REFERÊNCIAS}

1. Borenstein DG. Epidemiology, etiology, diagnostic evaluation, and treatment of low back pain. Curr Opin Rheumatol. 2001;13(2):128-34.

2. Larson JW 3rd, Levicoff EA, Gilbertson LG, Kang JD. Biologic modification of animal models of intervertebral disc degeneration. J Bone Joint Surg Am. 2006;88(Suppl 2):83-7.

3. Lotz JC. Animal models of intervertebral disc degeneration: lessons learned. Spine (Phila Pa 1976). 2004;29(23):2742-50.
4. Chiba K, Andersson GB, Masuda K, Momohara S, Williams JM, Thonar EJ. A new culture system to study the metabolism of the intervertebral disc in vitro. Spine (Phila $\mathrm{Pa}$ 1976). 1998;23(17):1821-7.

5. Ariga K, Yonenobu K, Nakase T, Hosono N, Okuda S, Meng W, et al. Mechanical stress-induced apoptosis of endplate chondrocytes in organcultured mouse intervertebral discs: an ex vivo study. Spine (Phila Pa 1976). 2003;28(14):1528-33.
6. Risbud MV, Di Martino A, Guttapalli A, Seghatoleslami R, Denaro V, Vaccaro AR, et al. Toward an optimum system for intervertebral disc organ culture: TGF-beta 3 enhances nucleus pulposus and annulus fibrosus survival and function through modulation of TGF-beta-R and ERK signaling. Spine (Phila Pa 1976). 2006;31(8):884-90.

7. Lee CR, Iatridis JC, Poveda L, Alini $\mathrm{M}$. In vitro organ culture of the bovine intervertebral disc: effects of vertebral endplate and potential for mechanobiology studies. Spine (Phila Pa 1976). 2006;31(5):515-22. 
8. Gantenbein B, Grünhagen T, Lee CR, van Donkelaar CC, Alini M, Ito K. An in vitro organ culturing system for intervertebral disc explants with vertebral endplates: a feasibility study with ovine caudal discs. Spine (Phila Pa 1976). 2006;31(23):2665-73.

9. An HS, Masuda K. Relevance of in vitro and in vivo models for intervertebral disc degeneration. $\mathrm{J}$ Bone Joint Surg Am. 2006;88(2):8894.

10. Wehling P. Transfer of genes to intervertebral disc cells: proposal for a treatment strategy of spinal disorders by local gene therapy. Joint Bone Spine. 2001;68(6):554 -6.

11. Natarajan RN, Ke JH, Andersson GB. A model to study the disc degeneration process. Spine (Phila Pa 1976). 1994;19(3):259-65.

12. Gruber HE, Johnson T, Norton HJ, Hanley EN Jr. The sand rat model for disc degeneration: radiologic characterization of age-related changes: cross-sectional and prospective analyses. Spine (Phila $\mathrm{Pa}$ 1976). 2002;27(3):230-4.

13.Zhang H, La Marca F, Hollister SJ, Goldstein SA, Lin CY. Developing consistently reproducible intervertebral disc degeneration at rat caudal spine by using needle puncture. J Neurosurg Spine. 2009;10(6):52230.

14.Han B, Zhu K, Li FC, Xiao YX, Feng J, Shi Z, et al. A simple disc degeneration model induced by percutaneous needle puncture in the rat tail. Spine (Phila Pa 1976). 2008; 3(18):1925-34.

15. Norcross JP, Lester GE, Weinhold $P$, Dahners LE. An in vivo model of degenerative disc disease. J Orthop Res. 2003;21(1):183-8.
16. Masuda K, Aota Y, Muehleman C, Imai $\mathrm{Y}$, Okuma $\mathrm{M}$, Thonar EJ, et al. A novel rabbit model of mild, reproducible disc degeneration by an anulus needle puncture: correlation between the degree of disc injury and radiological and histological appearances of disc degeneration. Spine (Phila Pa 1976). 2005;30(1):514.

17.Sato M, Asazuma T, Ishihara M, Ishihara M, Kikuchi T, Kikuchi M, et al. An experimental study of the regeneration of the intervertebral disc with an allograft of cultured annulus fibrosus cells using a tissueengineering method. Spine (Phila $\mathrm{Pa}$ 1976). 2003;28(6):548-53.

18.Sakai D, Mochida J, Yamamoto Y, Nomura T, Okuma M, Nishimura K, et al. Transplantation of mesenchymal stem cells embedded in Atelocollagen gel to the intervertebral disc: a potential therapeutic model for disc degeneration. Biomaterials. 2003;24(20):3531-41.

19.An HS, Takegami K, Kamada H, Nguyen CM, Thonar EJ, Singh K, et al. Intradiscal administration of osteogenic protein-1 increases intervertebral disc height and proteoglycan content in the nucleus pulposus in normal adolescent rabbits. Spine (Phila Pa 1976). 2005;30(1):2531.

20.Rousseau MA, Ulrich JA, Bass EC, Rodriguez AG, Liu JJ, Lotz JC. Stab incision for inducing intervertebral disc degeneration in the rat. Spine (Phila Pa 1976). 2007;32(1):17-24.

21.Singh K, Masuda K, An HS. Animal models for human disc degeneration. Spine J. 2005;5(6 Suppl):267S-79S.

22.Sobajima S, Kompel JF, Kim JS, Wallach CJ, Robertson DD, Vogt MT, et al. A slowly progressive and reproducible animal model of intervertebral disc degeneration characterized by MRI, X-ray and histology. Spine(Phila Pa 1976). 2005;30(1):15-24.
23.Kim KS, Yoon ST, Li J, Park JS, Hutton WC. Disc degeneration in the rabbit: a biochemical and radiological comparison between four disc injury models. Spine (Phila Pa 1976). 2005;30(1):33-7.

24. Ching CT, Chow DH, Yao FY, Holmes AD. Changes in nuclear composition following cyclic compression of the intervertebral disc in an in vivo rat-tail model. Med Eng Phys. 2004;26(7):587-94.

25.Hunter CJ, Matyas JR, Duncan NA. Cytomorphology of notochordal and chondrocytic cells from the nucleus pulposus: a species comparison. J Anat. 2004;205(5):357-62.

26. Hughes PC, Tanner JM. The assessment of skeletal maturity in the growing rat. J Anat. 1970;106(Pt 2):371-402.

27.Urban JP, Smith S, Fairbank JC. Nutrition of the intervertebral disc. Spine (Phila Pa 1976). 2004;29(23):2700-9.

28.Ferguson SJ, Ito K, Nolte LP. Fluid flow and convective transport of solutes within the intervertebral disc. J Biomech. 2004;37(2):213-21.

Correspondência:
Elaine Del Bel
Laboratório de Neurofisiologia Molecular
- MEF - Fisiologia FORP - USP
Avenida do Café, s/n
CEP 14040-904, Ribeirão Preto (SP),
Brasil.
E-mail: eadelbel@forp.usp.br

